\title{
THE IRISH DIMENSION TO DRUG USE AND HIV IN BRITAIN
}

This paper focuses on the issues facing Irish drug users who have migrated to Britain. The main finding is that a number of changes in relation to drug use occur as a result of migration itself. These are both harm increasing and harm reducing, hut a majority of respondents self-reported harm-increasing changes in drug use particularly in relation to HIV infection.

Irish drug users have close networks of friends and relatives that they can access when they come to Britain. However, there is evidence that they are reluctant to approach services. When they did so Irish drug users traveled long distances in London to go to services that were known to work with their community.

Together with the multiplicity of problems associated with migration that are described in this paper, the findings show that Irish drug users are a highly vulnerable group within the British drug-using population.

\section{Introduction}

The decision to focus on drugs during the Irish presidency of the European Community in 1996 and the murder in June 1996, of Veronica Guerin, a journalist committed to 'uncovering' Dublin's underworld of drug dealers, has brought an international spotlight on the drug issue in Ireland. There has been a rapid spiral of problematic drug use in Dublin since the early 1980s. This was initially heroin use concentrated in the disadvantaged housing areas in central Dublin and in the satellite housing estates on the periphery of the city. In the 1990s there are concerns about escalating problems associated with drugs throughout all sections of society. In this paper we look at some of the background issues to drug use in Ireland, the link to HTV/AIDS, and the impact these have had on Irish drug users living in Britain.

\section{The Irish in Britain}

The Irish, who have experienced migration over a long and continuous period of time, are a well established community in Britain. During the last 300 years a -» significant number of Irish people have migrated from Ireland, the majority of whom migrated to Britain. Due to lack of a consistent Irish category in ethnic monitoring

Oonagh O'Brien is an anthropologist who has specialized in migration and ethnic identity. She has worked in the field of HIV and drug use for 7 years and is currently completing a research project on Irish migrants and HIV at the Mortimer Market Centre, University College Medical School in London. Luke Tierney is a drug and HIV worker who has experience working in Ireland, England, and Malta. He has worked with Irish drug users in London since 1989 and has been involved in die research project on Irish migrants and HIV since its inception. Address correspondence and requests for reprints to Oonagh O'Brien, 79 Ashenden Road, London ES ODT.

it is difficult to obtain accurate figures but it is currently estimated that between Irish-born $(830,453$ in 1991 the census analysis, which is $1.52 \%$ of the population of Britain) and second generation there are up to 2 million Irish people in Britain, making them one of the largest ethnic minorities in Europe (Greenslade et al. 1991). Between 1981 and 1991 the Irish-born population in Britain grew by 1.5\% (Irish Trade Board 1993). This coincides with the period of the so called opiate epidemic in Dublin, 
when there was an explosion of opiate use and, for the first time, the emergence of a needle culture (Smyth and Thomas 1996; Butler 1991).

As a group, the Irish population has a distinct identity and historical set of experiences from the host population in Britain. There is evidence to suggest that Irish people experience disadvantage in the fields of housing, employment and health in Britain (see Action Group for Irish Youth [AGIY] 1992; Haringey Council 1991; London Irish Women's Centre 1993; O’Brien and Kahnl996). Althoughas an ethnic minority and migrant group Irish people have full legal rights in Britain, they make up the largest single ethnic group among the homeless, and a large proportion 'of Irish migrants come to Britain to work in unskilled work on building sites and roads. Raftery et al. (1990) have used census results to demonstrate that there is a marked deterioration in the health of first and second generation Irish people subsequent to migration to Britain. However, as well as this picture of disadvantage, Irish people also make important skills contributions to the British labor market, working in health and social services, the media, business, and a range of other occupations. It is a community that has developed its own services for Irish people in need. Traditionally these have centered around the Catholic Church and the Irish centers found in most large towns in the United Kingdom that as well as being a focus for cultural activities, also provide social services.

Drug users are part of this migratory pattern. In some cases drug use, or associated issues, are part of the push factors that have caused migration, but for many drug users, migration is a result of the same issues that affect any migrant: the need for employment, housing, and security. Drug users that migrate are typically long-term opiate users, many of whom stabilize on a Methadone prescription in Britain.

This paper is based on the experience and research findings of Positively Irish Action on AIDS (PIAA), a community-based voluntary organization in London that provided a support service for Irish people affected by HTV/AIDS in Britain from 1989 to 1996, focusing on drug users who used PIAA's services. Information is drawn from the monitoring system, research, and knowledge built up within the service. It examines the sociocultural issues pertinent to working with drug users from a particular ethnic group living in Britain.

\section{Drug Use and HIV/AIDS in Ireland}

The majority of Irish drug users in Britain started using drugs in Ireland and, therefore, it is it is useful to summarize some of the background issues related to drug use there. Although recreational drug use in Ireland has existed since at least the 1960s, problematic drug use commenced on a large scale in the early 1980s with an influx of heroin into Dublin. From 1979 onward there was a dramatic and largely unexpected growth in drug use, in particular injecting of heroin, in the Dublin area. Smyth and Thomas (1996:99) have written that at this time:

The opiate markets of the world were being flooded with heroin, initially after the overthrow of the Shah in Iran and somewhat later in conjunction with the Soviet invasion of Afghanistan. Drugs from both these sources provided a quick and effective way of making and keeping large sums of money. The impact of this increased supply of opiates was pronounced in many countries including Ireland where inner Dublin was especially affected.

These inner city areas of Dublin are characterized by poverty, high unemployment, and social exclusion. A series of research studies have shown that during the 1980s the growth in drug use occurred disproportionately among disadvantaged young people. O'Hare and O'Brien (1993:35) stated:

The characteristic of disadvantage which defines this group either in a personal way in being early school leavers and jobless; or environmentally in being over represented in those areas of the city associated with vandalism, unemployment, and a history of crime and drug use, has been one of the principal research findings from a range of studies in the Dublin area over the past ten years. 
An unpublished report by a special Governmental Task force on Drug Abuse (established in April 1983) acknowledged that drug problems in Dublin were largely explicable in terms of the poverty and poweriessness of a small number of working class neighborhoods (Butler 1991). A direct relationship between poverty, disadvantage, and drug use has been clearly demonstrated in other research projects (Dean et al. 1983; O'Kelly et al. 1988; McKeown et al. 1993). The timing and spread of this wave of drug use had unfortunate consequences; the injecting of heroin grew rapidly at the same time as HIV was, unknowingly, spreading through this group of drug users. By 1992 the Irish Department of Health Statistics showed that 300 people were diagnosed with AIDS, among whom $41 \%$ were injecting drug users (IDUs). Smyth and Thomas (1996) wrote that at this time only three European countries (Yugoslavia, Spain, and Italy) had reported a higher cumulative AIDS prevalence. Some areas of Dublin were particularly badly affected, with many households having at least one HTV-seropositive family member, and many with more than one member. Irish drug users have usually experienced multiple bereavement, with numerous friends and neighbors as well as brothers, sisters, or cousins and in-laws having died of AIDS-related illness.

\section{Epidemiology}

Because of the high rate of HIV among drug users, the general epidemiology of HTV in Ireland is much closer to the pattern found in Southern Europe than Northern Europe. It is distinctly different from England (where most Irish migrants have moved during the 1980s and 1990s) in a number of ways. Currently in Ireland the major route of HTV transmission has been through injecting drug use (fig. 1); this transmission route is given by over half the people with a known HTV diagnosis $(50 \%$ of the diagnoses in Ireland are attributed to injecting drug use compared with $10 \%$ in England). In England the overwhelming majority of people known to be seropositive attribute their infection to sex between men (21\% of diagnoses in Ireland are attributed to sex between men compared to $64 \%$ in England). The different epidemiology of HIV can also be seen in Irish migrants living in Britain and effective prevention, care, and support must take these differences into account.

Figure 1

\section{Comparison of Epidemiology, Ireland and England}

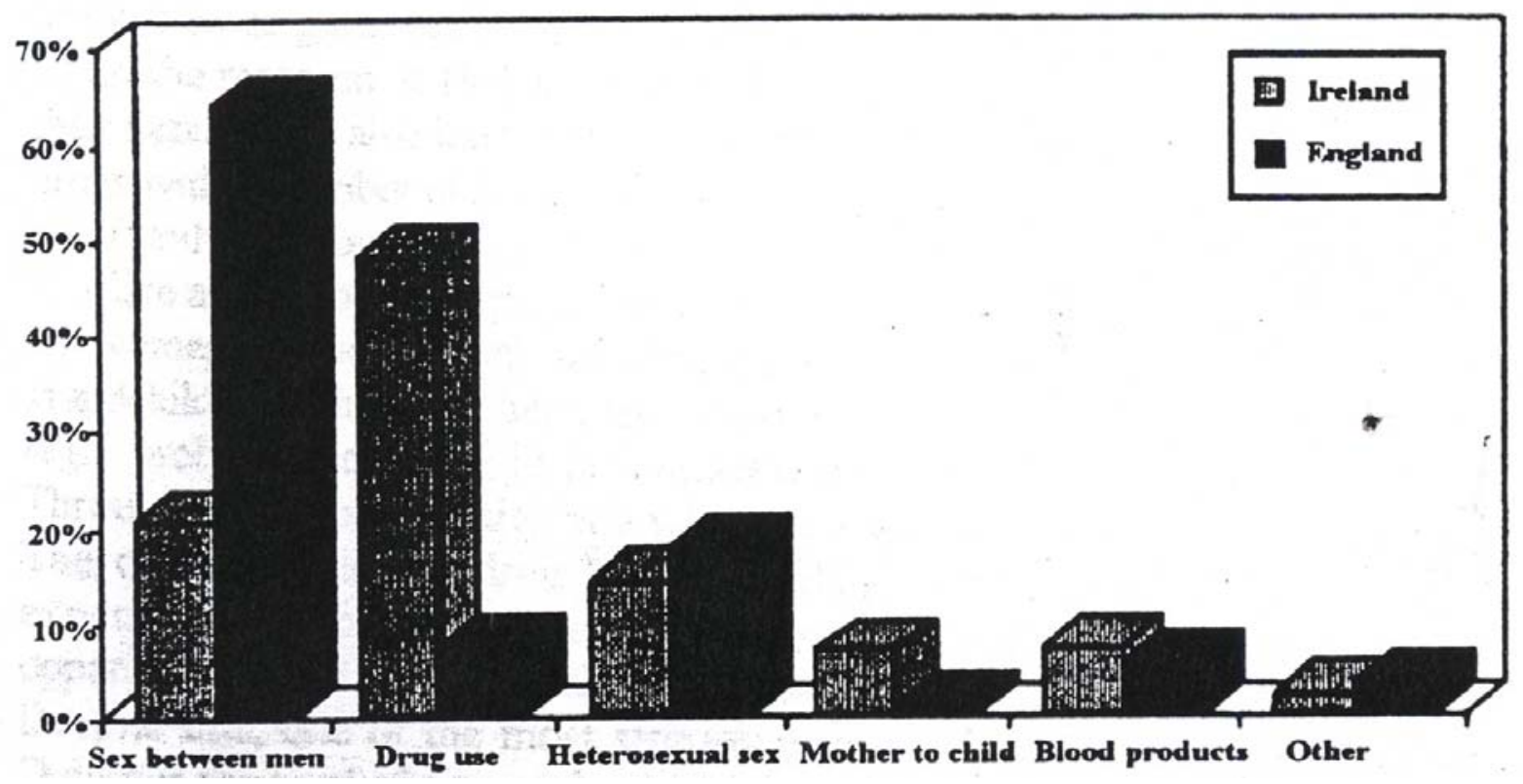


Total known numbers diagnosed as HIV positive: Ireland 1,799 (population 3.5 million) and England 26,873 (population 49 million). Sources: Irish figures are from the Department of Health (Ireland), August 1997. English figures are from the PHLS AIDS Centre, Communicable Disease Surveillance Centre, and Scottish Centre for Infection and Environmental Health; unpublished quarterly surveillance table no. 29, September 1995.

As there is no monitoring of Irish people being tested for HTV, it is impossible to know how many Irish people are living with HIV in England. There are potential risks related to HTV that might arise from people moving from an area of one type of epidemiology to an area with a different epidemiology. At PIAA we identified that within the migrant group there can be specific needs not addressed in the country of destination, and mobility itself might affect health behavior. Both of these issues are relevant for Irish people living with HTV in Britain (O’Brien 1993:2). Mobile populations experience other factors that can affect vulnerability to HIV including:

- $\quad$ lack of access to information and health care,

- $\quad$ linguistic and cultural differences in comprehending prevention messages, and

- $\quad$ articularities in living conditions and social and economic difficulties that could lead to high risk behaviors (Haour-Knipe 1995:199).

\section{Irish Women and HIV}

Because intravenous drug use has been the major route of transmission, proportionately more women are infected with HTV, either through drug use or sex with a drug-using partner, in Ireland than in England. In an MRC study of women living with HIV in Ireland and Britain, $68 \%$ of the women in Dublin were assigned to the transmission category of injecting drug use, compared with 22\% in England (United Kingdom Medical Research Council (MRC11996). It is regrettable that this study did not record how many of the women in the British clinics were Irish (as, for example, was done with African women) as an opportunity to compare and contrast women with HIV from Ireland and Britain was lost.

Because of the high proportion of women who are seropositive in Ireland (fig. 2), there is consequently a higher proportion of children both infected and affected by HIV. Although there are no official statistics released in Ireland on the number of women testing seropositive, St. James' hospital in Dublin has seen 830 patients who were diagnosed seropositive (over half of the Irish total) and 24\% of these are women. In England 13\% of those with a known HIV diagnosis are women ${ }^{1}$.

Figure 2

\section{Comparison of Women Diagnosed as HIV Positive}

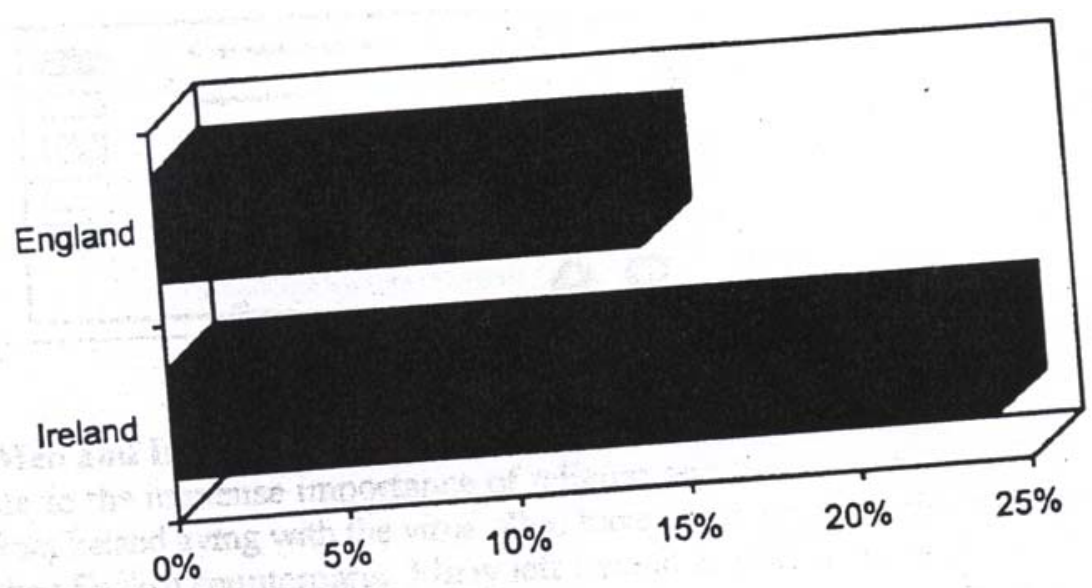




\section{Families and Community}

In addition, HIV regularly affects large family groups in Ireland. Many members of one family might be infected in certain neighborhoods of Dublin. Again this can be attributed to multiple drug use within families. The areas of Dublin most affected by drug use and HIV have many problems, but residents also live in an extremely close community network of kinship and neighborhood. A sizeable proportion of PIAA's service users originated from these communities, which are in highly specific geographical areas. They are already marginal to some extent from mainstream Irish society, and self reliant economically and in terms of support. Once it became clear that drug problems affected more or less every family in these communities in one way or another, support became available from the communities themselves to families caring for relatives ill from AIDS-related illness or hepatitis or looking after a chaotic drug user. In these areas people relate to each other in a variety of ways including through kinship, neighboihood, employment, generation, religion, socially, sexually, use of alcohol, use of drugs (including sharing injecting equipment), and support. The communities could be said to have multiple affiliations, some of which are associated with health risks and others with care and support. However, the majority of the affiliations, such as kinship or neighborhood, do not have any implications in terms of health or risk with regard to HIV. The lines of affiliation that do carry an associated health risk (drug use and sexual relationships) are unilinear in the sense that they exist through one peer group or generational group. They could be seen as horizontal, whereas the lines of support and care are vertical as they involve cross-generational kinship groups.

In the research at PIAA, $43 \%$ of those who used drugs had another member of their family who also had problems with drug use, and of those, over half had used drugs with a member of their family. Twenty two percent of respondents had at least one family member with an HTV diagnosis $(n=100)$.

Care and support is typically provided through the kinship network, in particular by women. Some women are caring for three or four children and up to seven grandchildren, who have been left without care givers because of illness and death, legal problems resulting in prison sentences, or migration (typically to Britain). Throughout the community as a whole, a devastating number of people have died. The overall picture of drug users in Ireland is of a group of people who have experienced serious disadvantage and poverty, with poor housing, employment opportunities, and state of health (for more information see McKeown at al. 1993). Despite this, one of the most striking aspects of the communities referred to in Dublin is the level of care and support that can be provided by kinship groups and neighbors. This level of support and care is seldom available when Irish drug users move to Britain. This can cause isolation and unhappiness and also internal conflict between wanting the better opportunities in Britain and at the same time the care and support received from family and neighbors back home.

Figure 3 is a kinship diagram of a typical family in Dublin, to show how kinship groups are affected by drug use and HIV on a wide scale. This diagram is not based on a real family, but represents how HIV might affect the wider kinship groups of an Irish migrant family living in Britain. It shows, in the shaded box, a woman and her two children who are living in London. She herself is ill from ATDS-related illness and her two children are HTV negative. She may present at an agency in London with a variety of needs triggered, for example, by a deterioration in health or problems accessing drug treatment. However, this woman also has many members other family who are infected or affected by HIV and AIDS. The diagram shows the woman as having two brothers and two sisters. One brother and one sister have already died from AIDS-related illness, and one brother is also diagnosed seropositive. There are children who have lost one or both parents, and children whose parents are periodically ill. Typically the grandmother will be involved in caring for them- hi addition the family members may well have married into families with similar patterns of HIV infection.

These complex familial relationships, with multiple experiences of bereavement and illness, are evident among many Irish people infected or affected by the HIV disease living in Britain. In addition they affect the service needs of Irish people. Although this pattern of infection in families may be familiar in a number of countries, it is not the case in England and, therefore, services are often not experienced or skilled in dealing with the consequences. It may be that there is flexible movement of 
children between family members in Ireland and Britain and that there are sudden and unplanned visits to Ireland that can last for some time when another family member is ill or has died or other family members are in need of services and/or support.

\section{Figue3}

\section{Kinship Diagram}

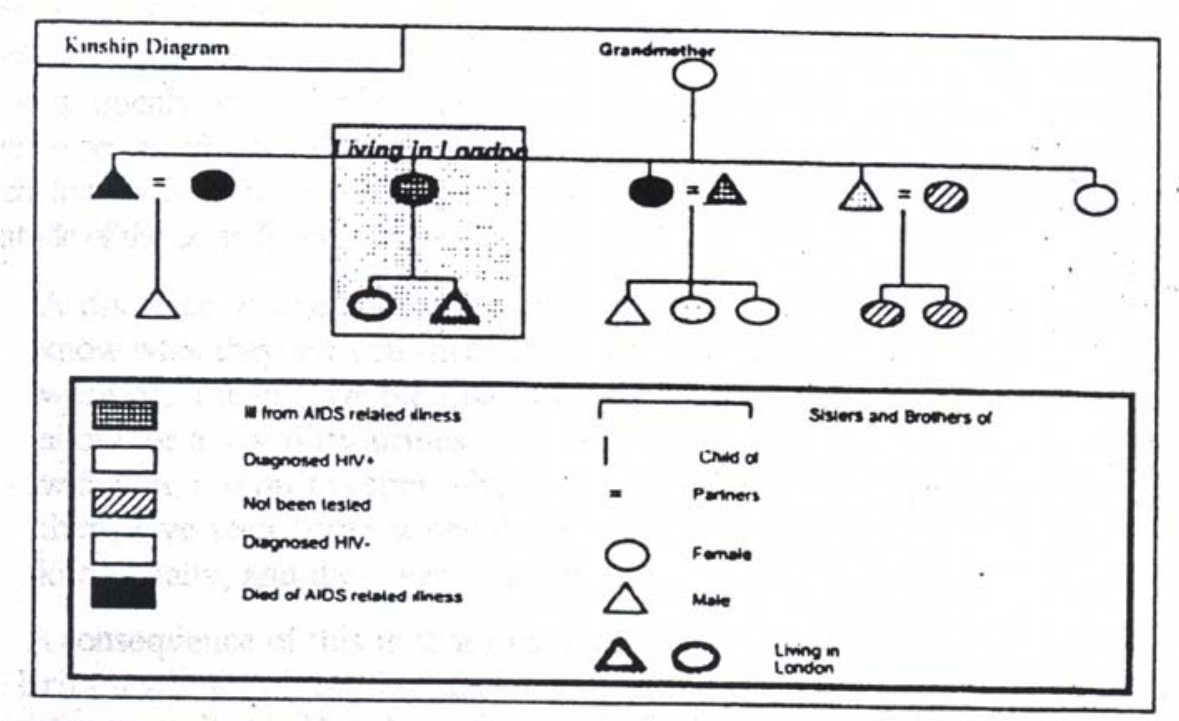

\section{Gay Men and Injecting Drug Use}

Due to the immense importance of religion and family within the culture, gay men from Ireland living with the virus often have a different experience of being gay from their English counterparts. Many left Ireland as sexual exiles yet most retain a strong identification to Irish ways and a genuine loyalty to family. Although it is well known that gay men use recreational drugs, there is rarely any discussion about gay men and injecting drug use. Riordan (1994) examined PIAA's monitoring of drug users during a 6 -month period $(\mathrm{n}=42)$ and found that $21 \%$ of the men who had a history of injecting drug use self-identified as gay and $2 \%$ self-identified as bisexual. Given the problems already mentioned about identifying as gay for an Irish man, and the additional inhibitions about discussing drug use openly in Ireland, discussed below, an Irish gay man who has a history of injecting use, or is currently injecting drugs that are not usually associated with the gay scene has needs that may go unnoticed and unmet. In some cases individuals connected the commencement of, and subsequent problems with, drug use to the problems associated with being gay in Ireland.

Because of the different pattern of HIV infection in Ireland and Britain, the different way in which the epidemic has affected women and families, the number of children affected, and the religious and cultural issues, it can be surmised that services in England, largely geared toward English gay men, are not necessarily appropriate either for the majority of heterosexual Irish men and women and their families, or for the special needs of seropositive Irish gay men and their families. Other people can also feel out of place in services due to their ethnicity or sexuality. Although there are services that cater to drug users and HP/ in England, many of these are for people still using drugs and there is a gap in services for ex-drug users, or those stabilized on a methadone prescription. The epidemic in England is concentrated within one group, gay men, and although mainstream HIV services do welcome drug users or ex-drug users, many Irish clients at PIAA expressed a feeling of discomfort in an overwhelmingly gay environment. This is reflected in the poor use of services by many Irish people. At PIAA, 50\% of new clients were not in contact with any services at first contact. This figure was stable over 5 years despite increasing numbers of new clients. In an article entitled The Forgotten Few, Drug Users with HIV, McNally (1996) writes of a conscious decision by British health 
authorities to abandon care for drug users with HIV. He argues that the general perception is that the interventions initiated to prevent HIV were successful and, therefore, although some primary prevention initiatives will continue, those who are already infected with HIV can be forgotten about within the overall success story:

ironically 'targeting' - assumed by most of us to mean that the different needs of different groups would be met appropriately - is now being used by some purchasers to choose between different groups of people with HIV...It now seems to be acceptable to remove funding entirely from specialist services for drug users with HIV(McNally 1996).

\section{Service Development in Ireland}

Irish drug users living in Britain have usually had their first experience of treatment in Ireland. These experiences have impacted on their drug-using behavior in Britain and the likely successiul outcome of treatment there. To understand the issues facing Irish drug users in British services, therefore, it is important to know some of the issues related to the development of services in Ireland. Butler and Woods (1992) have written that it was not until the late 1960s that there was any perception of a drug problem in Ireland. In 1971 a report on the Working Party on Drug Abuse was published in Ireland and was an important reference for drug policy throughout the 1970s. Butler (1991) writes that the report was clearly influenced by developments that had already occurred in Britain and the United States. In Britain a pragmatic approach to drug use was initially established by the Rolleston Committee in 1926, allowing for prescription of addictive drugs on an indefinite basis to stabilize drug users. This system was considerably tightened by the late 1960 s, with prescribing limited to specific doctors and clinics. In the United States, drug problems were made the explicit responsibility of the criminal justice system after the Harrison Act of 1914, with only a limited role for the health care system. However, Methadone prescribing was practiced much more widely in the United States by the 1960s. Butler writes that discussion of the long standing policy divergence between Britain and the United States was clearly lacking in the 1971 report, as was any discussion of the implications of this policy divergence for countries such as Ireland that were starting from zero. That is, countries that had no infrastructure of drug-treatment centers at this time in the area of drug policy (Butler 1991:214). Butler writes that it has continued to be the case that although the Irish policy makers have been open to influence from developments in other countries, they have been introduced after a considerable time lag.

Early services provided facilities for rehabilitation through therapeutic communities and addiction counselors. Harm reduction was introduced later, largely as a reaction to the realization of the extent of HIV infection among Dublin drug users. Due to the concentration on abstention and the medical model of addiction during the early to mid-1980s, there were limited facilities to cope with the problems associated with injecting drug use and policies and facilities developed in reaction to the awareness of a growing crisis in certain neighborhoods. Although well intentioned, prescribing policies that steered people toward a drug-free lifestyle inhibited them from talking freely about any illicit drugs being used in addition to their prescriptions. This inevitably led to an inability to deal openly about active drug use. A number of drug users who experienced this regime perceived it as judgmental, and felt that they were denied services that might help them live safely with their drug use. In a focus group at PIAA one member spoke of the attitude of the centralized drug services in Dublin during the 1980s, describing them as:

A disgrace, it was a disgrace, trying to get Methadone out of them, you know what they put you through, if you had one dirty urine you know you; were off. I mean, people that's trying to come off the heroin you have to allow for a few dirty urines, you know. And they just, if you had children with you, it didn't matter who you were, just cut off the bloody thing, and "then, I've seen some states there, some mothers going down crying you know really, and they were just cut off. 
A consequence of this is that many current or ex-drug users from Ireland living in Britain still find it hard to talk openly about their drug use. This inhibition has sometimes resulted in British professionals finding it hard to work with Irish clients because the experience of services in Ireland is not fully understood. The fear of having a prescription withdrawn, or being denied services, is still very present with some users, many years after they have left Ireland.

The co-existence of a series of events during the early 1980s such as the explosion of injecting drug use, restrictive access to drug treatment (which was not designed to cater to such large numbers), limited access to harm reduction (including clean needles and Methadone maintenance), and a general lack of education and training in harm-reduction techniques combined to result in the rapid spread of HIV and hepatitis (including hepatitis C) in the poorer districts of Dublin. Initially this rapid spread of HIV took those affected (and services) by surprise. HIV was seen as something that happened elsewhere and would not affect Ireland. In one focus group held at PIAA a member of the group reinforced this feeling when he said:

the one thing that lulled us into a false sense of security over here was that in the eighties, even though we knew about AIDS, it was an American ., problem, it was not something that was going to affect us here, and the -1 press picked up on that as well, and you know you were lulled into a false sense of security. fire."

Another member of the group described the spread of HIV in Dublin: "it really was like a bush

In 1982 The Ana Liffey Project, a city center street drug agency, opened and in 1989 the Merchants Quay Project, run by the Catholic Order, of The Franciscans, opened as a drug and HIV service. These two centers, along with other voluntary groups are committed to a non-judgmental, user-friendly approach. Other drug services are in the statutory sector, and although the government has increasingly committed itself to harm-reduction practices in drug treatment, there have been limited resources, and a lack of sustained development of services.

During the 1990s harm-reduction services have developed further, with needle exchanges throughout Dublin and Physeptone (Methadone) prescriptions available in central and satellite clinics in the Dublin area. However, these services are, at the time of writing, still not adequate for the high numbers of drug users in need of services in Dublin. In 1996 there were just under 1000 places for an estimated 7,000 drug users (this estimate by Murphy et al. 1992 and Bury and O'Kelly 1989). During the autumn of 1996, a mobile drug clinic was started for the first time in Dublin aiming to provide access to treatment including Methadone to those who cannot get access to oversubscribed services. During 1997 funding to drug-treatment services was dramatically increased, and service provision was estimated to be available for 4,000 drug users. Although this expansion $\mathrm{m}$ treatment is welcome, there are teething problems in managing such a dramatic expansion. In addition there are still gaps in services, particularly in the provision of clean injecting equipment and within the prison service. A wave of syringe robberies throughout Dublin has lead to popular demonstrations against these services, even though an estimated $20 \%$ of the robberies were conducted by drug users. Simultaneously, the murder of Veronica Guerin lead to the expansion of already existing vigilante groups particularly in the most affected areas of the city, which has lead to at least one death of a drug user who was supposedly dealing in drugs as well as a number of forced evictions. Clearly the lack of access to services and social pressures are factors that affect migration of this group. For those living in housing estates where drug use and associated crime have added to their problems, life has become almost unbearable in the face of what appears to be an unsolvable cycle of disadvantage.

\section{Irish Drug Users in Britain}

Irish drug users come to Britain for a variety of reasons some of which are related to drug use and others that are not. An action research project entitled The Mobility Project was initiated and conducted within PIAA. One hundred Irish people infected and affected by HIV were interviewed in depth as part of the project The interviews were based on self reporting and were conducted over the 
period of 1 year By locating the research within a community-based organization, information was also collected through ethnographic observation and networking as well as the interviews A series of focus groups was held to evaluate results. There was widespread evidence of drug use throughout the sample. Seventy seven respondents had used one of a list of drugs more than 5 times, and 47 respondents had a history of injecting drug use or were currently injecting drugs. Nineteen of these were women and 29 men. Twenty six stated that heroin was their main drug of use and 19 listed opiates other than heroin as a main drug of use. Forty-four had used crack more than 15 times. There was varied use of drugs among men who were identified as gay and, as might be expected, amphetamines was the main drug of use. However there was also heroin use among this group and five respondents with a history of injecting heroin were identified as gay.

The organization PLAA kept extensive monitoring systems over a 5-year period and they consistently showed that at any one time between a third and a half of PIAA's service users had a history of injecting drug use. Issues affecting drug users were necessarily important to the organization and featured prominently in the research project.

As part of the research project at PIAA respondents were asked why they left Ireland and why they came to Britain. The major reason given by Irish migrants for leaving Ireland (push factors) were economic (19\%). Equally important were problems with family and legal problems. Problems with drugs was a primary reason for leaving Ireland for only $7 \%$ of respondents, even though $48 \%$ of respondents were identified as current or ex-injecting drug users, and many others used drugs in some form. Despite the popular account that many people travel to Britain for improved HIV care, this was only an issue for $5 \%$ of respondents. When respondents were asked for the reasons for coming to the United Kingdom (pull factors), the close proximity and easy access to Britain was a major factor (19\%). Having contacts in Britain (friends) and economic reasons (looking for a job) were next in the order of priorities. Access to drug services was a major pull factor for only $7 \%$ of respondents, and general drug issues was a factor for a further $3 \%$.

In general, many of the problems affecting Irish people in Britain, which were outlined in the introduction, also affect Irish drug users. The research at PIAA found that respondents had experienced serious problems with accommodation. There were $19 \%$ with no fixed abode (NFA) at the time of interview and 33\% had been NFA prior to the interview, since coming to London. There was evidence that people were very ill-informed about the state benefit system in London, and most of them (34\%) obtained information about organizations that could help them through word of mouth, indicating that general information about drug use and services was reaching them through already existing community networks rather than outreach initiatives.

Another complication in the lives of a number of respondents was the issue of children. Forty nine percent of respondents had a total of 87 children. Thirty percent of parents where the main care giver is seropositive had made no plans for the future care of their children in the event of illness. However, the majority of respondents were not the main care givers of their children. Only $20 \%$ of children were looked after by the respondent. Sixty percent of the children were being looked after in Ireland by other relatives. Some of the siblings had been split up and were being cared for by different members of the family and, in general, children were moved quite frequently between Ireland and Britain. Irish drug users in London had serious problems with housing and accessing child care. Many were reluctant to approach social services for assistance because of their drug use and, therefore, emergency child care when mothers were ill involved sending the children 'home' to Ireland This was extremely disruptive to the children.

The report by Merchants Quay, which focuses on drug users in Dublin, shows that many of the current parents were also cared for by their grandparents or were in care as children. There appears to be a cycle of problems with adequate parenting that continues through the generations (McKeown et al.1993).

Most of the difficulties affecting Irish drug users in Britain are multiplied for women. The majority of the women who are seropositive in Ireland are thought to have become positive through injecting drug use (often sharing needles with a sexual partner, brothers and sisters, or friends, particularly those living in the same neighborhood) or through sex with an injecting drug user. 
Increasingly, women diagnosed seropositive in Ireland have no known risk factors, nor do their partners, indicating a worrying growth in the spread of HIV through heterosexual sex. In recent years condoms and clean needles have been available from satellite clinics and health boards. However, up until the mid-1990s these were not so easy to obtain. There were only a limited number of clinics, some in outlying areas, and they opened on different days of the week. The long term difficulties of accessing Irish services have made a lasting impact on these women. In one focus group at PIAA a women described the difficulties of traveling daily to centralized drugs services:

Sure there was the girls from Dun Laoghaire, and on Saturday and Sunday [name of service] shut at half twelve, they had to get in from Dun Laoghaire, some of them had three and four children and to get in all the way from Dun Laoghaire to get the little cup (ofmethadone), I mean they should have at the weekends gave it to them, or else let a chemist out there where they could just go and pick it up I mean, who wants to come in everyday, that's what you had to do.

In a country with a strong focus on religion and family, women felt themselves to be particularly harshly judged when they strayed from the path destined from them. One member of a focus group described this:

But I mean Ireland is always the same and you know the moral right and if you veered anywhere over to the center you had it, you had to work for everything you got.

There was particularly strong pressure on women to have children and to be mothers. Additionally, there was a strong cultural pressure against women using contraceptives, particularly condoms. One report quotes one Irish women as saying

You know, I've never used condoms at any time from the time I met him and I thought, I was saying, I felt I was belittling, insulting him. I thought meself, like maybe that I'm afraid, you know, I'm afraid because he has it [HIV infection] but I used to say leave it (Murphy-Lawless and Redmond 1993:56).

Irish women can find it difficult to find appropriate services that meet their needs in Britain. The problems that some Irish drug users have in accessing HTV services in England, mentioned above, are compounded for Irish women. Many women do not see mainstream HTV centers as a place where they will feel welcomed. Cultural issues also play their part Many women find the formal setting of services daunting or uncomfortable. Those who have previously been through drug programs often feel overly exposed to services (or, as commonly put, over social worked).

Over the 5 years that PIAA monitored service users, the number of women using the agency was always around $30 \%$ of the total, despite the fact that there was a high turnover of service users because of PIAA's policy of referring people into mainstream services. Between April 1995 and March 1996, 32\% of PIAA's 300 clients were women. When we examined monitoring in relation to current or ex drug users in depth, during a 6-month period, $43 \%$ of these were women. All of the women (but only $80 \%$ of the men) came from Dublin. Although the women made up less than half of the group, they were involved in $54 \%$ of service interventions. This indicates that women required a higher input of resources and face a wider range of issues (Riordan 1994:34). It also demonstrates that when services are women-friendly, culturally appropriate, and participatory, women affected by HTV/AIDS do make excellent use of service, alongside gay men and male drug users. In response to needs identified by service users, an Irish women's group was facilitated through PIAA. Informal social events were organized for Irish women who contacted the agency. Trips to the cinema or horse riding (horses are commonly found in poorer areas of Dublin, especially the outlying estates) provide a comfortable environment where women can support each other by exchanging information about their health, sharing stories about friends back home and engaging in conversation to lighten the daily load of living with the virus. 


\section{Irish Drug User Networks in Britain}

The majority of service users at PIAA came to know of the service through word of mouth. This fact reflects the community networks that many Irish people live within in Britain. Contacts with family or friends were of importance in providing accommodation, employment, and a social life to new arrivals. Drug users also make contacts through drug-using networks connected to their ethnic identity and culture. Even contact with Irish people who are strangers can be important in establishing networks. The account of arriving in London in the autobiography of Pat Tiemey, an Irish person who contracted HTV through drug use, demonstrates how meeting an Irish person, even one who is unknown, plays a role in integrating new arrivals into life in the new country (Tiemey 1993:72). Power (1995) has written about the ways in which drug users operate in networks. In the case where injecting drug use overlaps with ethnic identity, the networks can be very close knit indeed. Current or ex injecting drug users were asked, as part of the PIAA research, with whom they used drugs. Fifty seven percent of those responded that they only used drugs with other Irish people and only $9 \%$ said they used drugs with no other Irish people at all. The rest used with mixed communities. These answers give an indication of the close knit circles in which Irish drug users move in Britain and their detached nature compared to British drug users. In addition, it became clear that Irish drug users traveled long distances in London to go to services that were known to be sympathetic to them (see PIAA 1991).

\section{Service Use}

Commentators writing about general health issues affecting Irish people have commented on a reluctance to approach services. Although Irish people have more serious health issues affecting them, they visit the doctor less often than the general population in Britain (Kelleher and Hillier 1996:108). Helman quotes Zola who conducted a study of Irish Americans and found that of all the ethnic groups he was studying, Irish people tended to ignore and play down bodily complaints (Zola 1956 cited in Helman 1990:163). This is reflected in monitoring figures from PIAA, which showed that every year at least half of PIAA's new clients were not in contact with any other services in Britain. Many of them had been living in Britain for a long time, using drugs, and knowing that they had an H3V diagnosis. This information is even more worrysome when looking at the risk profile (fig. 4) of PIAA's service users with a history of injecting drug use during the last year of monitoring.

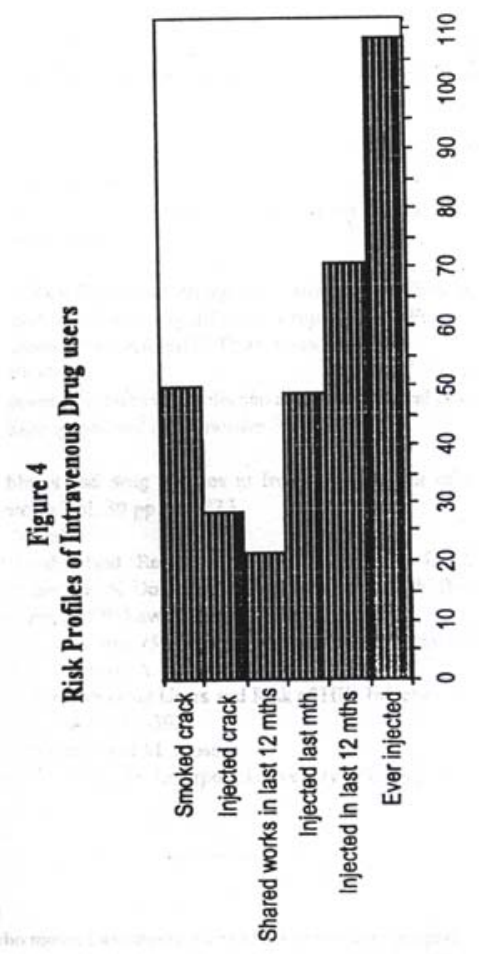


Data collected based on all 276 clients seen by PIAA in the first 11 months of the year 1995-\% show that $21 \%$ of adult clients were involved in crack use and $54 \%$ of these were injecting crack. Forty two percent of clients had a history of injecting drug use or were involved in drug use at the time of contacting PIAA. These data also show the risk profile of clients using the service in terms of injecting and sharing injecting equipment Fifty four percent of clients seen were not in contact with any other services in Britain when they first contacted PIAA.

\section{Conclusion}

Evidence from PIAA showed that drug use tends to become more harmful upon migration. Other factors indicate that culturally targeted services are of great importance in accessing and working successfully with this group. Given these circumstances it is essential that British drug services monitor their Irish clients carefully and assess needs to ensure that Irish clients are using and obtaining services that meet their needs.

Differences in drug use between Ireland and England were identified at PIAA, where front-line workers were particularly skilled at working with Irish drug users and were aware of some of the specific risks. (All reports by PIAA, including those listed in the reference section of this paper, are now available from The Action Group on Irish Youth, LVSRC, 356 HoUoway Road, London N7 6PA.) The following points, which apply to both men and women who use drugs or who are stabilized drug users, were identified (PIAA 1996:8).

- In Ireland drug users tend to use different drugs and/or use them at different strengths from drug users in Britain. Recently arrived Irish drug users cannot be assumed to have a street knowledge about the British drugs scene. Although evidence suggests that Irish drug users link into a subculture within a subculture, i.e., they mix largely with Irish people and within that, Irish drug users, it can take a while to become accustomed to the different drugs available and the different dangers associated with them.

- $\quad$ Heroin has tended to be purer and stronger in England than in Ireland, although during 1996 it is believed that stronger heroin is available in Ireland. However, fluctuations in purity and strength of street drugs in both Ireland and England put mobile active drug users at risk as their tolerance may be below parity "with the drugs with which they come into contact This can result in unexpected overdosing and destabilizing of drug use for newly arrived drug users.

- Temazepam is a drug that is unfamiliar to drug users in Ireland and, therefore, Irish drug users will not be aware of the dangers of thrombosis and the loss of limbs associated with injecting it

- In Ireland, heroin is the main drug of choice for most users and crack cocaine is not (at the time of writing, 1997) generally available in Ireland. Irish drug users may come across crack cocaine for the first time in England without being aware of the problems associated with the drug. Experience of working with Irish drug users has shown that there is a high rate of injecting crack cocaine, which is not apparently as common among British drug users. Irish crack cocaine users should, therefore, also be counseled about safe injecting and HIV prevention in relation to injecting.

- In Ireland drug users often use slow release morphine tablets (MST) tablets, which are not used in tile same quantities by their British counterparts. These are usually injected.

These differences mean that Irish drug users are at a high risk of overdosing and experiencing physical harm when using drugs in England. Together with the multiplicity of problems associated with migration that have been discussed in this paper, Irish drug users are a highly vulnerable group within the British drug-using population. 


\section{Note}

1. Figures from Maeve Foreman, St James Hospital, Irish Women and HIV presentation at HTV and Sexual Hearth: The Needs of Irish Women, Conference held by Open Doors Project and PIAA, January 1996,London.

\section{References}

O’Flynn, J., and D. Murphy eds.

1992 Resource Handbook: Data and Information on the Irish in Britain. London: Action Group for Irish youth.

Bloor. M.

1995 HTV Related Risk Behaviour among International Travellers: An overview. In The Economic and Social Impact of AIDS in Europe, eds. D. Fitzsimons, V. Hardy, and D. Tolle. London: National AIDS Trust, Cassell.

Bury, G., and F. O'Kelly

1989 Human immunodeficiency virus infection in Dublin general practice. Journal of the Royal College of general Practitioners 39:101-103.

Butler, S.

1991 Drug problems and drug policies in Ireland: A quarter of a century reviewed. Administration Vol. 39 pp 210-233.

Butler, S., and M. Woods

1992 Drugs, HIV and Ireland: Responses to women in Dublin. In AIDS: Women, Drugs and Social Care, eds. N. Dom, S. Henderson, and N. South. Brighton: Falmer Press.

Dean, G., J. Bradshaw, and P. Lavelle

1983 Drug Misuse in Ireland 1982-1983, Dublin:Medico Social Research Board. Goldberg, D.V., M.A Frischer, A Taylor,

1994 Mobility of Scottish Drug Users and Risk of HIV Infection. European Journal of Epidemiology 10(4):387-392.

Greenslade, L., M. Pearson, and M. Moss

1991 Irish Migrants in Britain. LiverpooLUniversity of Liverpool Occasional Papers in Irish Studies no 3.

Haringey Council

1991 Agenda for Change: Equal Opportunities, The Irish Dimension. London: Haringey Council.

Haour Knipe, M.

1995 People who move: Developing HIV/AIDS prevention programmes in multicultural settings. In The Economic and Social Impact of AIDS in Europe, eds. D. Fitzsimons, V. Hardy, and D. Tolley. London: National AIDS Trust, Cassell.

Helman, C.

1990 Culture Health and Illness; An Introduction for Health Professionals. London: Wright Press.

Irish Trade Board

1993 Irish Born Residents in Britain. London:Irish Trade Board.

Kelleher, D. and S. Hillier

1996 The Health of the Irish in England. In Researching Cultural Differences in Health, eds. D. Kelleher and S. Hillier. London: Routledge.

The London Irish Women's Centre

1993 Roots and Realities : A Profile of Irish Women in London 1993. London: The Irish Women's Centre.

McNally, D. 
1996 The Forgotten Few, Drug Users with HIV. Institute for the Study of Drug Dependence Drug Links November.

McKeown, K., G. Fitzgerald, and A. Deehan

1993 The Merchants Quay Project: A Drugs/HIV Service in the Inner City of Dublin. Dublin: Franciscan Friary Merchants Quay Project.

Murphy, M., K. Gaffney, O. Carey, E. Dooley, and F. Mulcahy

1992 The impact of HIV disease on an Irish prison population. International Journal of STD and AIDS 3:426-429.

Murphy-Lawless, J. and D. Redmond

1993 Facing the Reality; Living with HIV or AIDS. Dublin: Body Positive.

O'Hare, A, and M. O'Brien

1993 Treated Drug Misuse in the Greater Dublin Area 1991. Dublin: Health Research Board.

O'Brien, O.

1993 Assessing the impact of HIV on the Irish Community in Britain. London: Positively Irish Action on AIDS.

O'Brien, O., and S. Khan

1996 Stigma and racism as they affect minority ethnic communities. In Crossing Borders: Migration, Ethnicity and AIDS, eds. M- Haour-Knipe and R Rector. Brighton: Taylor and Francis.

O'Kelly, F., G. Bury, B. Cullen. G. and Dean

1988 The Rise and Fall of Heroin Use in an inner City Area of Dublin. Irish Journal of Medical Science 157:35-38.

Positively Irish Action on AIDS

1990 Responding to Minority Community Needs: The Irish and HIV Conference Report. London: Positively Irish Action on ADDS. Positively Irish Action on AIDS

1991 Irish Assessment Project, Submission to Brent HIV Centre. London: Positively Irish Action on AIDS. Positively Irish Action on AIDS

1996 Advice Information and Directory of Services by PIAA Staff Team. London: Positively Irish Action on AIDS.

Power, R. et al.

Coping with Illicit Drug Use, Centre for Research on Drug and Health Behaviour. London: The Tufnell Press.

Raftery, J., D.R Jones, and M. Rosato

1990 The Mortality of First and Second Generation Irish Immigrants. The Social Science Med 31(5):557-584.

Riordan, S.

1994 Evaluating a Community-Based Initiative: The Drugs and Mobility Project. London: Positivety Irish Action on AIDS.

Smyth, F., and R.W. Thomas

1996 Controlling HIV/AIDS in Ireland: The implications for health policy of some epidemic forecasts. Environment and Planning A (28):99-118.

Tierney, P.

1993 The Moon on my Back. Dublin: Seven Towers Publishing.

United Kingdom Medical Research Council

1996 The Study Group for the MRC Collaborative Study of HIV infection in Women 1996, Ethnic differences in women with HIV infection in Britain and Ireland. AIDS 10(1):89-93. 


\title{
RELUCTANT PARTNERS: TRENDS IN APPROACHES TO URBAN DRUG-TAKING IN CONTEMPORARY BRITAIN
}

\author{
Susanne MacGregor \\ This paper reviews recent trends in drug policy in Britain. It identifies the influence of \\ American perspectives in encouraging greater attention to prevention and a stress on \\ partnership. Receptivity to these influences is explained by reference to restructuring of \\ contemporary cities and to $\bullet$ wider developments in British urban policy.
}

\section{Introduction}

This paper explores the influence of American perspectives on recent developments in British drug policy. It describes a shift toward greater emphasis on prevention, particularly community-based, multi-agency approaches. The shift was prompted by awareness of changes in patterns of drug taking as described and analysed by writers like Parker (1987) and Pearson (1987) who had pointed in the 1980 s to the association between the dreadful conditions in impoverished areas (like Glasgow, south London, and Liverpool) and the rise of the new heroin user.

Griffith Edwards (1995) has deplored the older tradition in British research of focusing "on the individual abstracted from context", excluding the environment from the frame, and he has welcomed growing recognition of the influence of social and environmental processes in both the causation of drug misuse and in intervention strategies. But although there is support for the view that a continuum of need requires a continuum of response, differences remain between those involved in treatment and care services and those promoting community responses. These tensions are most evident in urban areas where the opposition between concepts of community and city is most highly concentrated.

\section{Community, the City and Drugs}

The opposition of community and city is an old one in sociological theory. Community represents images of traditional values, integration, collective responsibility, intolerance of difference, priority to informal relationships, and local variations in social provision. City represents new styles and tastes, individual freedom and responsibility, professional and formal means of care and control, and universal shared standards of provision, at least at the minimal level. Translated into debate about the locus of responsibility for social control and meeting need in the field of drug misuse, tensions arise in Britain between those working in the criminal justice system, led by the Home Office, and those working in the health and social services, linked through the Department of Health, local authority social service departments, and voluntary drug treatment and care agencies. A key issue is whether

Susanne MacGregor is Professor of Social Policy at Middlesex University. She is currently directing a research project funded by the Home Office on community involvement approaches to drug prevention in England. Address correspondence and requests for reprints to Susanne MacGregor, School of Social Science, Middlesex University, Queensway, Enfield, London ENS 4SF. 